AKSARA: Jurnal Ilmu Pendidikan Nonformal

P-ISSN 2407-8018 E-ISSN 2721-7310 DOI prefix $\underline{10.37905}$

Volume 08, (1), January 2022

http://ejurnal.pps.ung.ac.id/index.php/Aksara

\title{
Praktik Pelatihan Foto Produk Untuk Kinerja Pemasaran Produk Pada Usaha Mahasiswa Fakultas Ilmu Sosial Dan Ilmu Politik Universitas Diponegoro
}

\author{
Robetmi Jumpakita Pinem ${ }^{1}$, Dinalestari Purbawati ${ }^{2}$ \\ ${ }^{1,2}$ Departemen Administrasi Bisnis, Universitas Diponegoro \\ robetmi@lecturer.undip.ac.id
}

Received: 13 August 2021; Revised: 02 October 2021; Accepted: 28 December 2021

DOI: http://dx.doi.org/10.37905/aksara.8.1.563-568.2022

\begin{abstract}
Abstraksi
Pengabdian masyarakat, memberikan pemahaman kepada mahasiswa untuk pentingnya menyiapkan foto produk yang layak. Social media dan market place sebagai sarana untuk media pemasaran akan sangat membuthkan materi untuk menarik minat dari pembeli produk atau jasa yang ditawarkan kepada calon konsumen. Setelah melakukan branding, Hidden Labs melakukan maintaining sosial media dari kliennya. Hal ini dilakukan agar bisa menarik engagement dari banyak orang sehingga usaha tersebut bisa memiliki jangkauan yang lebih luas. Kesulitannya adalah lebih kepada sifat klien yang berbedabeda mengenai knowledge mereka tentang branding. Ada beberapa klien yang memiliki knowledge branding yang kurang akan lebih gampang dalam mengusung konsep, tetapi kelemahannya adalah brainstorming yang kurang. Kalau klien yang memiliki knowledge mengenai branding akan semakin banyak brainstorming dan terkadang menjadi lebih risky karena mereka sudah memiliki latar belakang dan pengetahuan mengenai branding.
\end{abstract} Keywords: photo produk, pemasaran, pelatihan

\section{Latar belakang}

Pada pengabdian semester pertama tim pengabdian masyarakat, memberikan pemahaman kepada mahasiswa untuk pentingnya menyiapkan foto produk yang layak. Social media dan market place sebagai sarana untuk media pemasaran akan sangat membuthkan materi untuk menarik minat dari pembeli produk atau jasa yang ditawarkan kepada calon konsumen. Social media dan marketplace yang terus berkembangkan memberikan peluang besar bagi pelaku ushaa termasuk mahasiswa yang ingin melakukan pemasaran melalui social media. Social media dan market place dengan jumlah pengguna yang sangat besar dan semakin baiknya infrastruktur di Indonesia maka semakin memudahkan generasi muda untuk bisa memulai usahanya.

Kemajuan di bidang infrastruktur internet di Indonesia memang sangat besar dampaknya bagi masyarakat. Keberadaan market place dan social media dapat diakses kapan dan dimana saja oleh pelaku usaha dan juga calon pembeli. Kondisi yang menguntungkan kedua belah pihak ini membuka peluang besar bagi pelaku usaha untuk memasarkan produknya secara online. Salah satu masalah utama dalam memasarkan produk adalah foto produk. Untuk memutuskan sesuatu setiap calon pembeli pasti akan melihat produk dari foto yang disajikan social media dan market place. Penting bagi pelaku usaha untuk menyajikan foto yang menarik dan dapat menarik minat calon pembeli karena foto yang asal jadi akan mengurangi minat beli calon konsumen. 
Sehingga, perlu adanya pemahaman dari pelaku usaha untuk menyajikan foto produk yang baik dan menarik bagi konsumen.

Pendidikan kewirausahaan yang diberikan pada kurikulum perkuliahan, bertujuan menstimulus para mahasiswa untuk menjadi entrepreneurship. Maka tidak terlepas pula para mahasiswa memiliki kebutuhan kepentingan untuk dibekali terkait digital marketing, salah satunya yaitu memiliki keterampilan fotografi.

\section{Tinjauan Pustaka}

\section{Digital Marketing}

Chaffey (2002) mendefinisikan pemasaran digital adalah penerapan teknologi dalam bentuk online channel (website, e-mail, database, dan digital TV termasuk di dalamnya blog, feed, podcast, dan jejaring sosial) yang berkontribusi dalam kegiatan pemasaran untuk memperoleh keuntungan dan mempertahankan konsumen dalam proses pembelian yang multi-channel dan daur hidup pelanggan melalui teknologi digital dan pendekatan yang terencana untuk meningkatkan kesadaran konsumen baik terhadap perusahaan, perilaku, dan loyalitas terhadap merek. Selain itu pemasaran digital dilakukan untuk menyampaikan pesan melalui kegiatan komunikasi dan layanan online yang terintegrasi untuk memenuhi kebutuhan pelanggan yang spesifik.

Sedangkan, menurut Heidrick \& Struggles (2009), berkembangnya digital marketing menawarkan akses baru pada dunia periklanan yang tidak perlu digemborgemborkan namun sangat berpengaruh. Hal ini mendorong para marketer di Asia untuk mengalihkan penggunaan budget dari marketing tradisional ke arah media teknologi yang lebih interaktif. Menurut Sanjaya \& Tarigan (2009), digital marketing adalah kegiatan pemasaran yang termasuk ke dalam kegiatan branding dengan menggunakan berbagai media berbasis web seperti blog, website, e-mail, adwords, ataupun jejaring sosial lainnya.

Tentu saja, digital marketing tidak hanya berbicara tentang marketing internet namun mengarah kepada kegiatan pemasaran yang terintegrasi, modern, dan menjangkau pasar yang lebih luas. Pada dunia bisnis secara umum, pemasaran digital dalam bentuk periklanan berbasis website, optimasi mesin pencari (SEO), PPC advertising, pemasaran afiliasi dan kemitraan strategis, serta hubungan masyarakat online belum banyak dilakukan dalam mengkomunikasikan saluran penjualan online yang dikelolanya.

\section{Hasil}

Service yang diberikan adalah social media maintenance, creative campaign ads, dan juga branding. Hal yang paling difokuskan dari bisnis yang dijalankan adalah branding karena ini merupakan aspek penting, Hidden Labs ini akan membuat branding untuk usaha mulai dari logo sampai branding untuk usaha tersebut. Urban Sweet Supply merupakan projek pertama Hidden Labs untuk branding pada Oktober 2020, mereka diminta untuk branding untuk dessert bar. Urban Sweet Supply merupakan brand baru yang ingin mengangkat Croffle sebagai produk unggulannya, Hidden Labs membranding Urban Sweet Supply dengan warna dan ciri khas dari Urban Sweet Supply.

Pitch deck merupakan isi presentasi kalian yang akan dinilai dan dihargai oleh klien dengan harga yang tidak kecil. Branding untuk sebuah restoran dimulai dari brand naming atau penamaan suatu usaha itu sendiri. Contohnya adalah "White Bone" ini merupakan branding, dan juga memiliki brand positioning yaitu tagline dari bisnis atau 
usaha itu sendiri. Hal terpenting dalam branding adalah brand tone of voice atau penegasan dari branding seperti contohnya dalam White Bone adalah "elegant and quirky" yang mengusung tema Asia dan elegan.

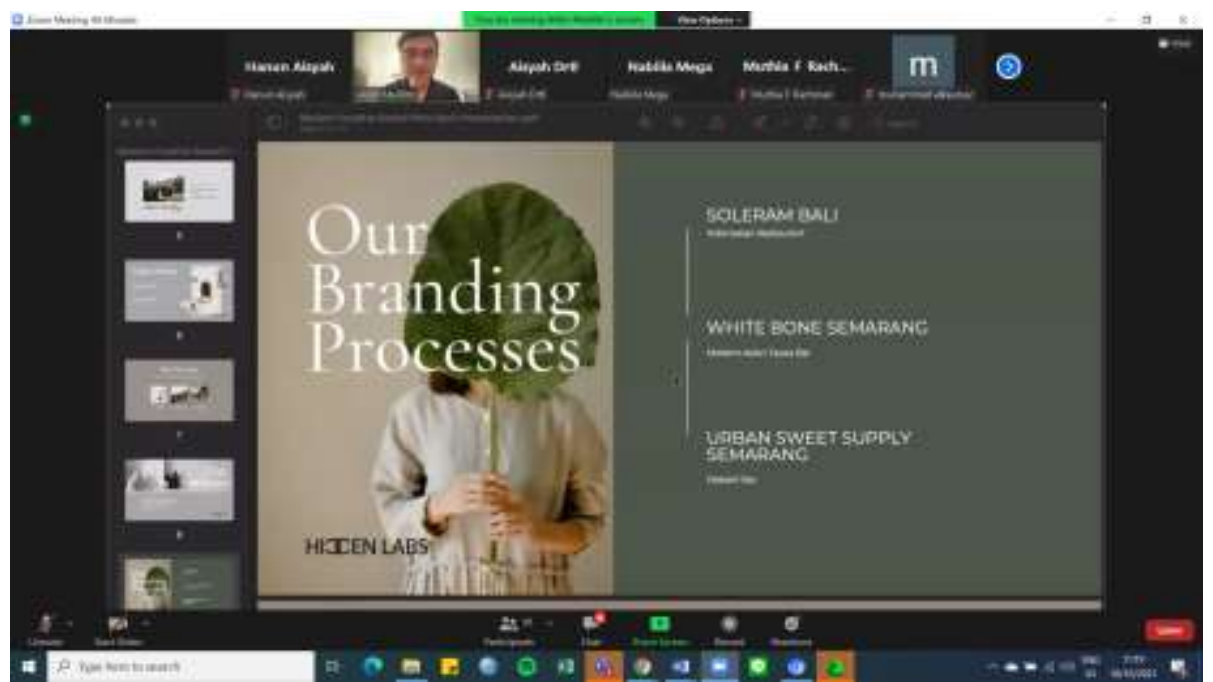

Gambar 1. Pelatihan Photo Produk Photo Sebagai Branding

Setelah dapat brand tone of voice, akan mendapat gambaran untuk membuat pelanggan mendapat feeling elegant and quirky. Hal ini disebut dengan Mood References yang kemudian didapat Icon Anatomy. Icon anatomy merupakan pemilihan icon untuk usaha tersebut yang sesuai dengan objektif usaha itu sendiri. Terdapat hal yang tidak boleh dilakukan dalam membuat logo, dan sangat perlu untuk diperhatikan sebuah usaha yang ingin membuat logonya. Hal-hal yang tidak boleh dilakukan karena dikhawatrikan bisa menghilangkan arti dan makna serta identitas dari usaha itu sendiri sehingga susah untuk dikenali.

Setelah melakukan branding, Hidden Labs melakukan maintaining sosial media dari kliennya. Hal ini dilakukan agar bisa menarik engagement dari banyak orang sehingga usaha tersebut bisa memiliki jangkauan yang lebih luas. Kesulitannya adalah lebih kepada sifat klien yang berbeda-beda. Mengenai knowledge mereka tentang branding, ada beberapa klien yang memiliki knowledge branding yang kurang akan lebih gampang dalam mengusung konsep, tetapi kelemahannya adalah brainstorming yang kurang. Kalau klien yang memiliki knowledge mengenai branding akan semakin banyak brainstorming dan terkadang menjadi lebih risky karena mereka sudah memiliki latar belakang dan pengetahuan mengenai branding.

Hal berharga yang dikatakan Aldin, pemilik Hidden Labs adalah mereka bisa mendapatkan kesempatan untuk merasakan pengalaman baru seperti mengunjungi kota baru yang belum pernah dikunjungi. Bisnis yang sekarang sedang dijalani adalah Hiddenlabs yang dimana berkecimpung di dunia branding berbagai jenis bisnis yang ada sebagai salah satu branding agency. Introduction: In digital world, there is a lot of hidden potential, yang dimana di dunia digital saat ini banyak sekali hal-hal potensial yang bisa dilakukan. Selain menjalankan bisnis sebagai branding agency, Aldin Meidito juga turut mengelola akun instagram yang kini menjadi banyak sorotan anak muda di kota Semarang yakni @hiddengemsemarang, dimana di instagram tersebut memuat banyak 
sekali foto dan referensi bagi audiensnya terkait tempat-tempat untuk nongkrong dan mungkin juga tempat bekerja yang ada di Semarang.

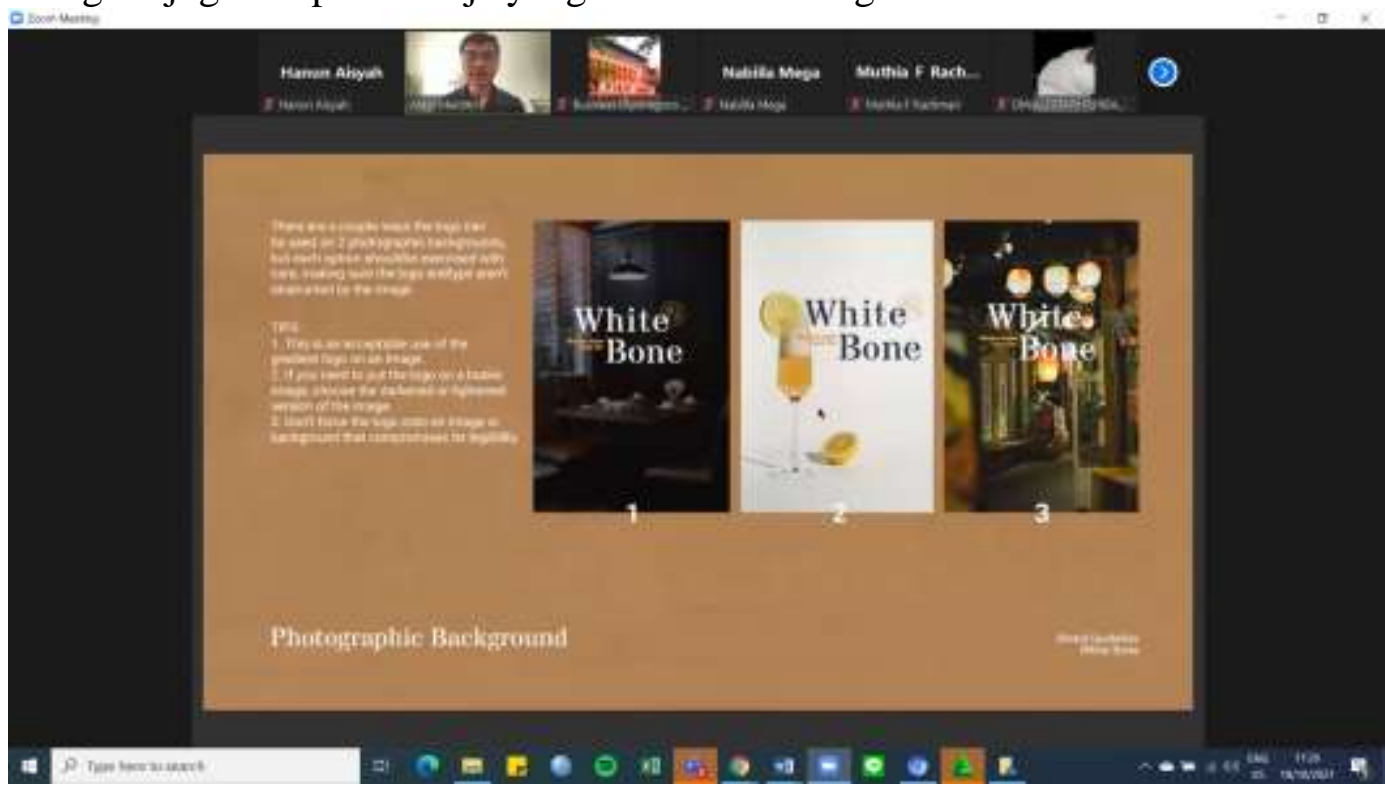

Gambar 2. Salah satu Client Photo Produk

Pada pelatihan foto produk ini dijelaskan pula terkait salah satu bisnis yang memang sedang dipegang oleh Hidden Labs di bidang branding, advertising dan social media management, yaitu White Bone Semarang yang dimana semua halnya dimulai dari penamaan bisnis White Bone sendiri merupakan gambaran hasil produk yang ditawarkan oleh bisnis tersebut.

Dalam hal pembuatan logo dari White Bone sendiri memiliki banyak makna yang terkandung yang berkaitan dengan produk dan bisnisnya itu sendiri dimana ada dua komponen yang terkandung dalam logo White Bone yaitu tulisan china dari kata putih dan juga gambaran dari binatang yang sangat dekat dan relate dengan White Bone itu sendiri yaitu gajah. Dimana disini kata dalam bahasa china itu dapat menjelaskan sebuah brand yang elegant, kemudian gambar gajah yang dapat menggambarkan brand tersebut yang quirky dan gabungan dari keduanya yang merupakan logo dari White Bone itu sendiri menggambarkan hasil yang cheeky. Disini dalam penyusunan dari logo dari White Bone itu menggunakan gabungan dari berbagai icon anatomy yang ada.

\section{Kesimpulan}

Berdasarkan hasil evaluasi terhadap kegiatan pengabdian masyarakat yang mengangkat tema Meningkatkan Pemahaman Foto Produk Untuk Kinerja Pemasaran Produk Pada Usaha Mahasiswa Fakultas Ilmu Sosial dan Ilmu Politik Universitas Diponegoro, maka dapat disimpulkan sebagai berikut,

a. Kegiatan Peningkatan Pemahaman Foto Produk Untuk Kinerja Pemasaran Produk Pada Usaha Mahasiswa Fakultas Ilmu Sosial dan Ilmu Politik Universitas Diponegoro telah berjalan dengan baik.

b. Adanya kebutuhan pembinaan digital produk terhadap mahasiswa Fakultas Ilmu Sosial dan Ilmu Politik Universitas Diponegoro untuk memperkaya dan meningkatkan kinerja pemasaran produk. 


\section{Saran}

Berdasarkan kesimpulan di atas, maka terdapat beberapa saran yang diajukan, antara lain sebagai berikut:

a. Departemen Administrasi Bisnis perlu melaksanakan kegiatan pelatihan digital produk secara berkelanjutan untuk peningkatan peran tenaga akademik dalam melaksanakan Tri Dharma Perguruan Tinggi khususnya dalam dharma Pengabdian Kepada Masyarakat.

b. Departemen beserta pihak stakeholders dapat melanjutkan hasil-hasil kegiatan pengabdian yang telah dilaksanakan pada periode sebelumnya dengan programprogram lanjutan sehingga memberikan dampak yang lebih signifikan.

c. Sasaran pelatihan harus lebih banyak menjangkau berbagai bidang usaha

\section{Daftar Pustaka}

Beechler, S., \& Woodward, I. C. (2009). The global "war for talent." Journal of International Management, $15(3)$, 273-285. https://doi.org/10.1016/j.intman.2009.01.002

Chaffey, D. (2002). eMarketing eXcellence: Planning and Optimizing Your Digital Marketing. http://www.uah.es/biblioteca/ayuda_formacion/estilos_citas.html

Heidrick, I., \& Struggles. (2009). Boards in Turbulent Time. Corporate Governance Report. http://www.uah.es/biblioteca/ayuda_formacion/estilos_citas.html

Kingsnorth, S. (2016). Digital Marketing Strategy. An Integrated Approach to Online Marketing.

Rowley, J. (2004). Online Branding. Online Information Review, 28(2), 131-138. https://doi.org/10.1108/14684520410531637

Ryan, D. (2009). Understanding Digital Marketing: Marketing Strategies for Engaging the Digital Generation. Kogan Page Limited Second.

Sanjaya, R., \& Tarigan, J. (2009). Creative Digital Marketing Teknologi berbiaya Murah, Inovatif dan Berdaya hasil gemilang. PT Elex Media Komputindo. http://www.uah.es/biblioteca/ayuda_formacion/estilos_citas.html

Tarigan, J., Purbo, O., \& Sanjaya, R. (2010). Business Driven Information System. PT Elex Media Komputindo.

Ward, M. R., \& Lee, M. J. (2000). Internet Shopping, Consumer Search and Product Branding. Journal of Product \& Brand Management, 9(1), 6-20. https://doi.org/10.1108/10610420010316302

Yasmin, A., Tasneem, S., \& Fatema, K. (2015). Effectiveness of Digital Marketing in the Challenging Age: An Empirical Study Afrina. International Journal of Management Science And Business Administration, 1(5), 69-80. http://researchleap.com/category/international-journal-of-management-scienceand-business-administration 
AKSARA: Jurnal Ilmu Pendidikan Nonformal

P-ISSN 2407-8018 E-ISSN 2721-7310 DOI prefix $\underline{10.37905}$

Volume 08, (1), January 2022

http://ejurnal.pps.ung.ac.id/index.php/Aksara 